\title{
Short communication: Added value of rumination time for the prediction of dry matter intake in lactating dairy cows
}

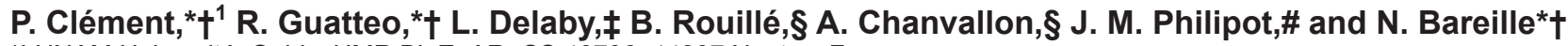 \\ *LUNAM Université, Oniris, UMR BioEpAR, CS 40706, 44307 Nantes, France \\ †INRA, UMR1300 BioEpAR, CS 40706, 44307 Nantes, France \\ fINRA, AgroCampus Ouest, UMR1348 Pegase, F-35590 Saint-Gilles, France \\ §Institut de l'Elevage, 149 rue de Bercy, 75595 Paris, France \\ \#Evolution, 69 rue de la Motte Brûlon, 35700 Rennes, France
}

ABSTRACT

The objective of the current study was to quantify the change in the prediction of dry matter intake (DMI) resulting from the inclusion of rumination time (RT) in the 2001 National Research Council (NRC) DMI prediction model. Forty-one Holstein cows fed the same total mixed ration were involved in a 10-wk study. Individual DMI were measured daily. The accuracy and precision of the original NRC prediction model, based on body weight, fat-corrected milk, and week of lactation as independent variables, was compared with the accuracy and precision of the same model with RT as an additional independent variable. The RT estimate was significant in the model developed but had a low value $(0.031 \mathrm{~kg} / \mathrm{h})$. Root mean square prediction errors were very similar in the 2 models $(1.70$ and $1.68 \mathrm{~kg} / \mathrm{d})$ as were the other indicators $\left(\mathrm{R}^{2}\right.$, linear bias, random error, and concordance correlation coefficient) selected to compare the models in this study. These results indicate no gain in DMI prediction precision or accuracy when RT is included in the NRC model.

Key words: dry matter intake, dairy cow, rumination, intake prediction

\section{Short Communication}

Prediction of DMI is important for the formulation of nutritionally and economically optimized diets in dairy cows. Extensive research effort has been made to develop a DMI prediction model that would be accurate over lactation for a large variety of diets. It has, however, proven difficult to create a general and accurate model due to the complex interactions between animal and feed factors (Huhtanen et al., 2011), which are poorly understood. Many models have been developed and adapted to a particular country or system for

Received December 20, 2013.

Accepted July 7, 2014.

${ }^{1}$ Corresponding author: pierre.clement@oniris-nantes.fr calculating nutritional requirements, but none of them can be used worldwide because they are insufficiently flexible to be accurate and precise in multiple different farming and feeding systems. Some models only include animal factors, such as milk yield, stage of lactation, or BW (NRC, 2001; Fox et al., 2004), whereas others include feed factors, such as digestibility of OM, NDF content, and feed DM content (Lewis, 1981; Huhtanen et al., 2011), in addition to animal factors. Simple models with few input variables lack accuracy, with mean biases of 1 or $2 \mathrm{~kg}$ of DMI/d. On the other hand, more complex models may be more accurate and have mean biases $<1 \mathrm{~kg}$ of DMI/d (Huhtanen et al., 2011; Krizsan et al., 2014) but are less suitable for on-farm application as they require large amounts of input data concerning diet characteristics.

In recent years, a rumination sensor has been developed (HR-Tag, SCR Engineers Ltd., Netanya, Israel). It enables the continuous recording of individual rumination times (RT) with high accuracy (Schirmann et al., 2009). Rumination time is influenced by diet composition; for example, NDF content (Adin et al., 2009). Thus, RT could be seen as an on-animal measure that is linked to diet composition and might improve existing DMI prediction models. Many studies have evaluated the effect of diet composition and diet particle size on DMI or RT, but data are scarce concerning the relationship between these 2 variables for cows fed the same TMR. Hasegawa et al. (1997) suggested that RT may be used to assess DMI, and Krause et al. (2002) found a positive relationship between long-particle DMI and RT. More recently, Schirmann et al. (2012) found that daily RT and DMI, in 42 dry Holstein cows, were not correlated across cows but were weakly negatively correlated within cow. Moreover, little attention has been paid to the relationship between DMI and RT during lactation. A positive relationship would be expected, because a longer rumination time may be necessary to process a growing amount of food.

The objective of this study was to investigate the putative gain, in terms of DMI prediction accuracy and 
precision, provided by the inclusion of $\mathrm{RT}\left(\mathbf{N R C}_{\mathbf{R T}}\right.$ model) in an existing and widely used prediction model developed in the United States by the National Research Council (NRC, 2001).

Forty-one (14 primiparous and 27 multiparous) Holstein cows at the experimental farm Les Trinottières $\left(47^{\circ} 34^{\prime} \mathrm{N} ; 0^{\circ} 23^{\prime} \mathrm{W}\right.$, Maine-et-Loire, France) were included in the study. The cows were housed in cubicles and fed a TMR for a 10-wk period between April and July 2011. The TMR was formulated according to the recommendations provided by the French National Institute for Agricultural Research (INRA, 2010), and cows were fed ad libitum once a day at approximately $1300 \mathrm{~h}$ to achieve $10 \%$ refusals on an as-fed basis. The diet was $71.8 \%$ corn silage, $1.7 \%$ straw, and $26.5 \%$ concentrate mix (rapeseed based) on a DM basis $(\mathrm{CP}=$ $14.1 \%, \mathrm{NDF}=43.2 \%$ of $\mathrm{DM}$ ). Individual amounts of feed offered and refusals were weighed daily, and TMR samples were taken daily and dried at $105^{\circ} \mathrm{C}$ for $24 \mathrm{~h}$ to determine the DM content. Daily individual DMI was calculated for each cow by subtracting the refusals from the TMR offered.

To monitor RT, all cows were fitted with a rumination logger (HR-Tag, SCR Engineers Ltd.) supported by a neck collar. The logger contains a microphone that records RT continuously and summarizes it into 2-h intervals (Schirmann et al., 2009). Two-hour-interval RT were summed between $1200 \mathrm{~h}$ on day $n$ and $1200 \mathrm{~h}$ on day $n+1$ to obtain individual daily RT.

Cows were milked twice daily at 0700 and $1700 \mathrm{~h}$, and daily yield was recorded using milk meters. Samples were collected weekly at 4 consecutive milkings and assessed for fat content using infrared analysis (AOAC International, 1997), results being summarized for each animal as a weekly mean. Fat-corrected milk was calculated daily as $\mathrm{FCM}=(\mathrm{kg}$ of milk $\times 0.4)+(\mathrm{kg}$ of milk $\times$ fat $\left.\%_{\text {week }} / 100 \times 15\right)$, where fat $\%_{\text {week }}$ is the weekly mean milk fat percentage (Gaines, 1928). Daily FCM and $\mathrm{RT}$ values were averaged to obtain weekly means.

Individual $\mathrm{BW}$ were measured every 3 to $5 \mathrm{wk}$ (wk $-3,2,7$, and 10 of the trial) at the same time of day. Weekly BW were calculated by linear interpolation between 2 measurements.

The experimental unit was the cow-week. In a first step, RT variance was decomposed using PROC VARCOMP (SAS version 9.2; SAS Institute Inc., Cary, $\mathrm{NC)}$ to estimate the variability linked to animal number, week of lactation (WL), and residual variability, for descriptive purposes. In a second step, 2 models, $\mathrm{NRC}$ and $\mathrm{NRC}_{\mathrm{RT}}$, were compared:

$$
\begin{gathered}
\mathrm{DMI}=\left(0.372 \times \mathrm{FCM}+0.0968 \times \mathrm{BW}^{0.75}\right) \\
\times\{1-\exp [-0.192 \times(\mathrm{WL}+3.67)]\}(\mathrm{NRC}), \text { and }
\end{gathered}
$$

$$
\begin{gathered}
\mathrm{DMI}=\left(0.372 \times \mathrm{FCM}+0.0968 \times \mathrm{BW}^{0.75}\right) \\
\times\{1-\exp [-0.192 \times(\mathrm{WL}+3.67)]\} \\
+\mathrm{a} \times \mathrm{RT}\left(\mathrm{NRC}_{\mathrm{RT}}\right),
\end{gathered}
$$

where DMI is the average daily DMI for $1 \mathrm{wk}$, and FCM is expressed in $\mathrm{kg} / \mathrm{d}, \mathrm{BW}$ in $\mathrm{kg}$, and $\mathrm{RT}$ in $\mathrm{h} / \mathrm{d}$. The constant "a" was estimated using PROC REG (SAS version 9.2; SAS Institute Inc.).

Two criteria were calculated to assess and compare the goodness of fit of the models: the $\mathrm{R}^{2}$ value of the regression between observed $(\mathrm{Oi})$ and predicted $(\mathrm{Pi})$ values; and the root mean square prediction error (RMSPE), calculated as RMSPE $=$ square $\operatorname{root}[\Sigma(\mathrm{Oi}$ $-\mathrm{Pi})^{2} / \mathrm{n}$ ], where $\mathrm{n}$ is the number of observations. The statistical significance of the mean bias and linear bias were estimated as proposed by St-Pierre (2003). The mean square prediction error was divided into 3 components: mean bias, linear bias (the deviation of the slope from 1), and random variation around the regression line (Bibby and Toutenberg, 1977). Further, the synthetic index for assessing the accuracy and precision, the concordance correlation coefficient (CCC), was calculated for each model as proposed by Lin (1989).

Because of technical problems with some of the rumination monitoring devices, 13 animals only had RT recordings for 4 to $9 \mathrm{wk}$ of the trial. Weeks without RT data were excluded from the analyses. Descriptive statistics of the 371 cow-weeks included in the analyses are provided in Table 1 . We detected no linear relationship between the mean time spent ruminating and the mean DMI calculated at the cow level over the trial (Figure 1). The mean RT measured in this study was $7.5 \pm 0.1 \mathrm{~h} / \mathrm{d}$. For individual cows, the mean RT over the trial ranged from 3.8 to $9.7 \mathrm{~h} / \mathrm{d}$, which is wider than that reported by Soriani et al. (2012) in early lactation (from 6.7 to $11.4 \mathrm{~h} / \mathrm{d}$ ). In our study, we observed high variability in RT between cows. Indeed, across cows, $84.1 \%$ of RT variability was linked to animal number and $0.5 \%$ to week, with $15.4 \%$ being residual variability. The variability linked to animal and week were, respectively, 72.4 and $12.3 \%$ for DMI, and 85.7 and $3.3 \%$ for FCM. The coefficient of variation $(\mathbf{C V})$ for RT $(22.7 \%)$ was higher than the CV obtained for DMI or FCM (10.4 and 14.1\%, respectively). At the cow level, the between-week CV was, on average, $8.9 \%$ (range $=3.6$ to $19.2 \%$ ) for RT, $5.2 \%$ (range $=1.9$ to $10.4 \%$ ) for DMI, and $5.0 \%$ (range $=1.8$ to $10.4 \%$ ) for FCM. Thus, for a given cow, RT was less repeatable between weeks than DMI or FCM. This is surprising because the main factors known to influence rumination activity, such as diet digestibility, diet fibrosity index (Sauvant et al., 1990), NDF intake (Adin et al., 2009), forage quality (Welch and Smith, 1970), heat 
Table 1. Descriptive statistics (mean, SD, minimum, maximum) of the variables included in the models $(\mathrm{n}=$ 371 cow-weeks)

\begin{tabular}{lcccc}
\hline Variable & Mean & SD & Minimum & Maximum \\
\hline DMI (kg/d) & 25.9 & 2.66 & 19.4 & 33.1 \\
FCM (kg/d) & 34.0 & 4.76 & 22.9 & 47.7 \\
Rumination time (h/d) & 7.5 & 1.70 & 2.7 & 11.2 \\
DIM (d) & 210 & 43.6 & 85 & 308 \\
BW (kg) & 697 & 65.8 & 538 & 865 \\
\hline
\end{tabular}

stress (Soriani et al., 2013), and regrouping (Schirmann et al., 2011), were stable in our study. This higher CV might partly be due to imprecision in the RT measurements. Even though good correlations $\left(\mathrm{r}=0.93, \mathrm{R}^{2}=\right.$ 0.87 ) have been obtained between HR-Tag measures and visual observation (Schirmann et al., 2009), the RT measure is probably less accurate and precise under field conditions than those of approved milk yield recording devices. Within-cow variability of RT might be a problem for practical implementation of a model with RT as an input. Indeed, past or present RT would be used in the model because future RT would not be known at the time of prediction, as occurs when milk yield is used as an input variable (Ingvartsen, 1994).

Many authors have studied the effect of differences in diet composition on RT but our study is the first to evaluate the relationship between DMI and RT for lactating cows fed the same TMR. As a basis, we used the NRC model (NRC, 2001), which has been widely used as a reference for the evaluation of new models (Halachmi et al., 2004; Shah and Murphy, 2006; Huhtanen et al., 2011). On the one hand, it is easy to implement because as input data it only uses "animal factors which would be easily measured or known" (NRC, 2001). On the other hand, the NRC model has been shown to clearly over-predict DMI when the diets used for evaluation are composed of silages other than those used for the development of the model (Huhtanen et al., 2011). In this case, inaccuracies of the model could be due to the fact that it does not include diet-related factors. Another limitation of this model is that milk yield is used as an input variable. Milk yield is a function of the genetic merit of the cow and the quality of the diet. As a consequence, when current diet deviates from the economically optimal diet, using actual milk yield as an input variable can result in seriously biased intake predictions (Friggens et al., 1998), as discussed by Krizsan et al. (2014).

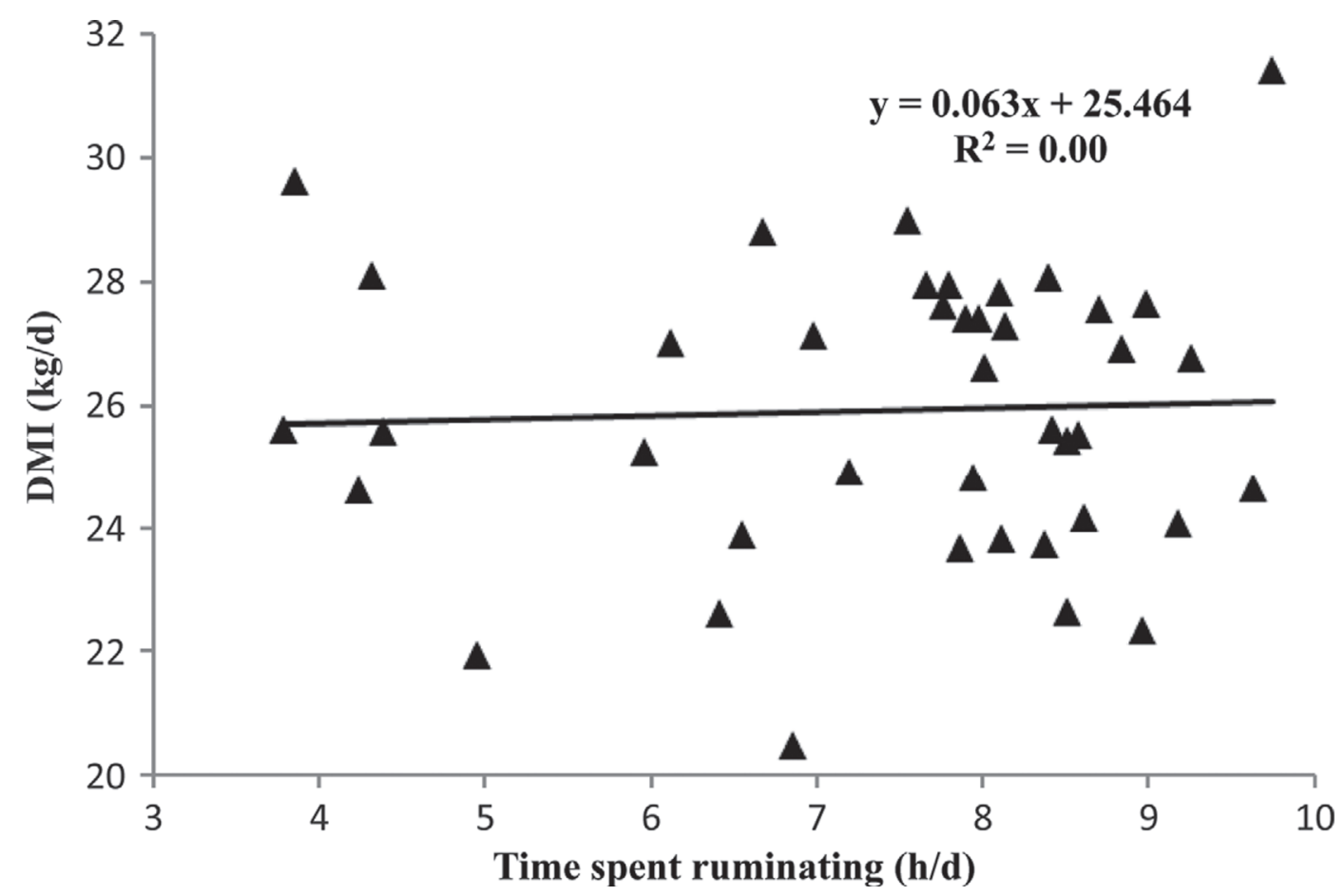

Figure 1. Scatterplot representing average time spent ruminating $(\mathrm{h} / \mathrm{d})$ against average DMI $(\mathrm{kg} / \mathrm{d})$ over the trial $(\mathrm{n}=41 \mathrm{cows})$. 
Table 2. Statistical values obtained for NRC (2001) and $\mathrm{NRC}_{\mathrm{RT}}$ models fitted to weekly DMI of individual cows, and accuracy and precision of the 2 models

\begin{tabular}{|c|c|c|c|c|c|c|c|c|c|}
\hline Model $^{1}$ & $\begin{array}{l}\text { RT estimate } \\
\text { (SE) }\end{array}$ & $\begin{array}{l}\text { Mean bias } \\
\quad(\mathrm{kg} / \mathrm{d})\end{array}$ & $\begin{array}{l}\text { Linear } \\
\text { bias }\end{array}$ & $\begin{array}{c}\mathrm{RMSPE}^{2} \\
(\mathrm{~kg} / \mathrm{d})\end{array}$ & $\mathrm{R}^{2}$ & $\mathrm{CCC}^{3}$ & \multicolumn{3}{|c|}{ Error distribution } \\
\hline NRC (2001) & - & $P=0.01$ & $\begin{array}{r}-0.06 \\
P>0.05\end{array}$ & 1.70 & 0.60 & 0.76 & 0.02 & 0.00 & 0.98 \\
\hline $\mathrm{NRC}_{\mathrm{RT}}$ & $\begin{array}{c}0.031 \\
(0.0114)\end{array}$ & $\begin{array}{r}-0.02 \\
P>0.05\end{array}$ & $\begin{array}{r}-0.06 \\
P>0.05\end{array}$ & 1.68 & 0.60 & 0.76 & 0.00 & 0.01 & 1.00 \\
\hline
\end{tabular}

${ }^{1}$ The $\mathrm{NRC}_{\mathrm{RT}}$ model added rumination time (RT) to the NRC (2001) model.

${ }^{2} \mathrm{RMSPE}=$ root mean square prediction error.

${ }^{3} \mathrm{CCC}=$ concordance correlation coefficient according to Lin (1989).

In the $\mathrm{NRC}_{\mathrm{RT}}$ model, the estimate for $\mathrm{RT}$ was low $(0.031 \mathrm{~kg} / \mathrm{h} ; P<0.01)$ but significantly different from zero (Table 2). This result is not consistent with the result obtained by Schirmann et al. (2012), who found no relationship between daily RT and DMI during the dry period. In $\mathrm{NRC}$ and $\mathrm{NRC}_{\mathrm{RT}}$ models, we observed a tendency for residuals to decrease when WL increased $(-0.07 \mathrm{~kg} / \mathrm{WL} ; P<0.001)$. Thus, in both models, DMI was underestimated when WL was $<30$ and overestimated otherwise. However, as this relationship was similar in the 2 models, it was still relevant to compare their goodness of fit. Residuals were not related to other independent variables.

The accuracy and precision of the $\mathrm{NRC}$ and $\mathrm{NRC}_{\mathrm{RT}}$ models were compared based on $\mathrm{R}^{2}$, mean bias, and RMSPE calculations, as summarized in Table 2. The goodness of fit in our study $\left(\mathrm{R}^{2}=0.60\right.$ for NRC model) was better than that obtained by Shah and Murphy
(2006) with a larger data set $\left(\mathrm{R}^{2}=0.42\right)$ in early lactation. The difference in mean DIM $(210 \mathrm{~d}$ in our study vs. $35 \mathrm{~d}$ in the study of Shah and Murphy, 2006) may partly explain the poorer fit obtained by Shah and Murphy (2006), because DMI increases less quickly than milk yield during early lactation. Accordingly, it is more difficult to predict DMI accurately and precisely during this period. The number of data sets used (1 data set in our study vs. 2 data sets originating from 2 farms in the study by Shah and Murphy, 2006) and the differences in diet composition may also contribute to the difference in goodness of fit. On the other hand, compared with our results, Huhtanen et al. (2011) obtained a higher $\mathrm{R}^{2}(0.73)$. This may be attributable to the differences in diet composition between the 2 studies.

The plot used for $\mathrm{NRC}_{\mathrm{RT}}$ bias decomposition is displayed in Figure 2. The mean bias value was higher in

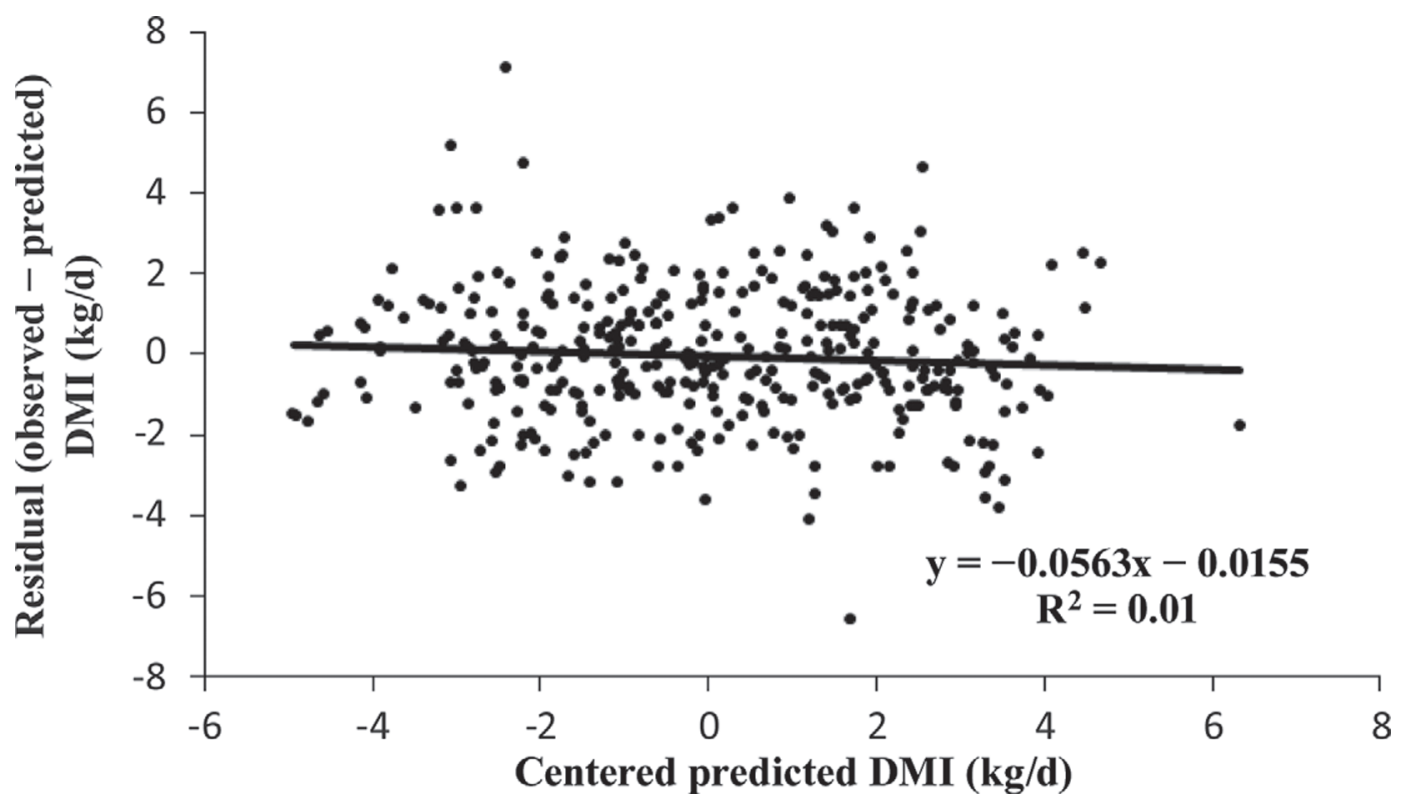

Figure 2. Scatterplot representing residual DMI $(\mathrm{kg} / \mathrm{d})$ against centered predicted DMI $(\mathrm{kg} / \mathrm{d})$ obtained with the $\mathrm{NRC}_{\mathrm{RT}}$ model, which added rumination time (RT) to the NRC (2001) model ( $\mathrm{n}=371$ cow-weeks). 
the NRC model $(0.22 \mathrm{~kg} / \mathrm{d} ; P<0.05)$ than in the NR$\mathrm{C}_{\mathrm{RT}}$ model $(-0.02 \mathrm{~kg} / \mathrm{d} ; P>0.05)$. This result was due to the fact that, in the $\mathrm{NRC}_{\mathrm{RT}}$ model, the constant "a" was calculated to center the distribution of residuals around zero. Thus, a lower mean bias was expected for this model. The RMSPE values were very similar (1.70 and $1.68 \mathrm{~kg} / \mathrm{d}$, respectively) in the 2 models (Table 2), as were $\mathrm{R}^{2}$ values $(0.60)$. The very high proportion of random error (0.98 for NRC model and 1.00 for $\mathrm{NRC}_{\mathrm{RT}}$ model) indicates the absence of systematic errors in both models. Thus, the statistics selected for this study were consistent and confirmed that no gain in accuracy and precision in DMI prediction was achieved when RT was added to the NRC model.

In conclusion, in this study, the RT estimate (0.031 $\mathrm{kg} / \mathrm{h}$ ) was significant in the DMI prediction model developed, but the addition of RT to the model had no effect on the accuracy and precision of the indicators studied. Moreover, the variability of RT between weeks for a given cow fed the same TMR might make it difficult in practice to include RT in a DMI prediction model.

\section{ACKNOWLEDGMENTS}

The authors thank Trinottières farm staff for their help, particularly with data recording. Help from Anne Lehebel (INRA, UMR1300 BioEpAR, CS 40706, Nantes, France) with statistical analyses was also very much appreciated.

\section{REFERENCES}

Adin, G., R. Solomon, M. Nikbachat, A. Zenou, E. Yosef, A. Brosh, A. Shabtay, S. J. Mabjeesh, I. Halachmi, and J. Miron. 2009. Effect of feeding cows in early lactation with diets differing in roughageneutral detergent fiber content on intake behavior, rumination, and milk production. J. Dairy Sci. 92:3364-3373.

AOAC International. 1997. Official Methods of Analysis. 16th ed. AOAC International, Gaithersburg, MD.

Bibby, J., and H. Toutenberg. 1977. Prediction and Improved Estimation in Linear Models. John Wiley \& Sons Ltd., Chichester, UK.

Fox, D. G., L. O. Tedeschi, T. P. Tylutki, J. B. Russell, M. E. Van Amburgh, L. E. Chase, A. N. Pell, and T. R. Overton. 2004. The Cornell Net Carbohydrate and Protein System model for evaluating herd nutrition and nutrient excretion. Anim. Feed Sci. Technol. 112:29-78.

Friggens, N. C., G. C. Emmans, I. Kyriazakis, J. D. Oldham, and M. Lewis. 1998. Feed intake relative to stage of lactation for dairy cows consuming total mixed diets with a high or low ratio of concentrate to forage. J. Dairy Sci. 81:2228-2239.

Gaines, W. L. 1928. An efficiency formula for dairy cows. Science $67: 353-354$.

Halachmi, I., Y. Edan, U. Moallem, and E. Maltz. 2004. Predicting feed intake of the individual dairy cow. J. Dairy Sci. 87:22542267.

Hasegawa, N., A. Nishiwaki, K. Sugawara, and I. Ito. 1997. The effects of social exchange between two groups of lactating primiparous heifers on milk production, dominance order, behavior and adrenocortical response. Appl. Anim. Behav. Sci. 51:15-27.

Huhtanen, P., M. Rinne, P. Mantysaari, and J. Nousiainen. 2011. Integration of the effects of animal and dietary factors on total dry matter intake of dairy cows fed silage-based diets. Animal 5:691-702.

Ingvartsen, K. L. 1994. Models of voluntary food intake in cattle. Livest. Prod. Sci. 39:19-38.

INRA (Institut National de la Recherche Agronomique). 2010. Alimentation des bovins ovins et caprins. Besoins des animaux - Valeur des aliments-Tables INRA 2007. Editions Quae, Versailles, France.

Krause, K. M., D. K. Combs, and K. A. Beauchemin. 2002. Effects of forage particle size and grain fermentability in midlactation cows. II. Ruminal pH and chewing activity. J. Dairy Sci. 85:1947-1957.

Krizsan, S. J., A. Sairanen, A. Hojer, and P. Huhtanen. 2014. Evaluation of different feed intake models for dairy cows. J. Dairy Sci. 97:2387-2397.

Lewis, M. 1981. Equations for predicting silage intake by beef and dairy cattle. Pages 35-36 in Summary of the 6th Silage Conference, Edinburgh, UK. The West of Scotland Agricultural College, Auchincruive, UK.

Lin, L. I. 1989. A concordance correlation coefficient to evaluate reproducibility. Biometrics 45:255-268.

NRC. 2001. Nutrient Requirements of Dairy Cattle. 7th rev. ed. Natl. Acad. Press, Washington, DC.

Sauvant, D., J. P. Dulphy, and B. Michalet-Doreau. 1990. The fibrosity index of ruminant feed and diet. INRA Prod. Anim. 3:309-318.

Schirmann, K., N. Chapinal, D. M. Weary, W. Heuwieser, and M. A. G. von Keyserlingk. 2011. Short-term effects of regrouping on behavior of prepartum dairy cows. J. Dairy Sci. 94:2312-2319.

Schirmann, K., N. Chapinal, D. M. Weary, W. Heuwieser, and M. A. G. von Keyserlingk. 2012. Rumination and its relationship to feeding and lying behavior in Holstein dairy cows. J. Dairy Sci. 95:3212-3217.

Schirmann, K., M. A. G. von Keyserlingk, D. M. Weary, D. M. Veira, and W. Heuwieser. 2009. Technical note: Validation of a system for monitoring rumination in dairy cows. J. Dairy Sci. 92:6052-6055.

Shah, M. A., and M. R. Murphy. 2006. Development and evaluation of models to predict the feed intake of dairy cows in early lactation. J. Dairy Sci. 89:294-306.

Soriani, N., G. Panella, and L. Calamari. 2013. Rumination time during the summer season and its relationships with metabolic conditions and milk production. J. Dairy Sci. 96:5082-5094.

Soriani, N., E. Trevisi, and L. Calamari. 2012. Relationships between rumination time, metabolic conditions, and health status in dairy cows during the transition period. J. Anim. Sci. 90:4544-4554.

St-Pierre, N. R. 2003. Reassessment of biases in predicted nitrogen flows to the duodenum by NRC 2001. J. Dairy Sci. 86:344-350.

Welch, J. G., and A. M. Smith. 1970. Forage quality and rumination time in cattle. J. Dairy Sci. 53:797-800. 